\title{
Effect of moisture dependent thermal and hygric parameters on the moisture and temperature fields in multi-layered systems of building materials
}

\author{
V. Kočí, J. Maděra, T. Korecký, M. Jerman \& R. Černý \\ Faculty of Civil Engineering, Department of Materials Engineering \\ and Chemistry, Czech Technical University in Prague, Czech Republic
}

\begin{abstract}
Thermal and hygric properties of porous materials depend on the content of moisture present in their pore system. As they appear as input parameters of computational models of heat and moisture transport, neglecting this dependence can affect the results of computational simulation of both hygrothermal performance and energy balance. In this paper, several multi-layered systems of building materials are analyzed. The hygric and thermal properties of materials forming the particular systems are determined at first. Then, the effect of their dependence on moisture content on the moisture and temperature fields is analyzed using a computational model. The consequences of neglecting the dependence of the particular parameters on moisture content are discussed and recommendations for the energy-related assessments of the studied multi-layered systems are formulated.
\end{abstract}

Keywords: computational modelling, thermal parameters, hygric parameters, moisture.

\section{Introduction}

On a theoretical level, most currently used computational models of heat and moisture transport can be considered as appropriate for predicting hygric and thermal conditions in building envelopes. However, any model can provide reliable information only in the case that the quality of input data is very good. This is not always true because the standard list of thermal and hygric parameters 
given by the producers as well as the material databases included in the simulation tools are usually far from complete. They also often do not include the dependencies of heat and moisture transport and storage parameters on moisture and temperature. Therefore, in today's scientific practice the computational simulations of temperature and moisture fields are performed either with moisture dependent parameters, constant parameters or partially moisture dependent, partially constant parameters, based on the availability of measured data. This makes comparisons of simulated data difficult even for experienced scientists, not speaking of building professionals in construction companies.

This paper brings a comparison of simulation results based on constant and moisture dependent input parameters. This allows emphasizing the differences between both approaches and contributes to a possible avoidance of design errors caused by poor quality of input data of computational models.

\section{Computational analysis}

The computational analysis was accomplished by computer code HEMOT [1, 2], which was developed at the Department of Material Engineering and Chemistry, Faculty of Civil Engineering, Czech Technical University in Prague on the basis of the general finite element package SIFEL [3]. As basic input parameters of the mathematical model, material parameters, scheme of construction detail, initial and boundary conditions and time specification of simulation were required.

\subsection{Mathematical model}

Künzel's mathematical model of heat and moisture transport [4] was used in the simulations which can be formulated as

$$
\begin{gathered}
\frac{d \rho_{v}}{d \varphi} \frac{\partial \varphi}{\partial t}=\operatorname{div}\left[D_{\varphi} \operatorname{grad} \varphi+\delta_{p} \operatorname{grad}\left(\varphi p_{s}\right)\right] \\
\frac{d H}{d T} \frac{\partial T}{\partial t}=\operatorname{div}(\lambda \operatorname{grad} T)+L_{v} \operatorname{div}\left[\delta_{p} \operatorname{grad}\left(\varphi p_{s}\right)\right]
\end{gathered}
$$

where $\rho_{v}$ is the partial density of moisture, $\varphi$ relative humidity, $\delta_{p}$ permeability of water vapour, $p_{s}$ partial pressure of saturated water vapour, $H$ enthalpy density, $L_{v}$ heat of evaporation, $\lambda$ thermal conductivity and $T$ temperature,

$$
D_{\varphi}=D_{w} \frac{d \rho_{v}}{d \varphi}
$$

is liquid moisture diffusivity coefficient, $D_{w}$ is capillary transport coefficient. 


\subsection{Scheme of construction detail}

Three variations of building envelope based on autoclaved aerated concrete (AAC) were chosen for simulation, in order to analyze the consequences of dependence of materials parameters on moisture content on the calculated moisture and temperature fields in a building envelope. We assumed load bearing wall in a thickness of $375 \mathrm{~mm}$ provided with three different types of thermal insulations (expanded polystyrene, hydrophobic and hydrophilic mineral wool) $50 \mathrm{~mm}$ thick. Thermal insulation was connected to the wall using adhesive layer made from Mamut M2 mortar in a thickness of $10 \mathrm{~mm}$. The whole building envelope was provided on the interior and exterior side with MVR Uni plaster (developed especially for AAC constructions).

\subsection{Material parameters}

All the material parameters were measured in the laboratory of transport processes at the Department of Materials Engineering and Chemistry, Faculty of Civil Engineering, Czech Technical University in Prague [5-7]. They are summarized in Tables 1 and 2 and Figure 1 where the following symbols are used: $\rho$ - bulk density $\left[\mathrm{kg} / \mathrm{m}^{3}\right], \psi$ - porosity [\%], $c$ - specific heat capacity $[\mathrm{J} / \mathrm{kgK}], \mu$ - water vapour diffusion resistance factor [-], $w_{\text {hyg }}-$ hygroscopic moisture content by volume $\left[\mathrm{m}^{3} / \mathrm{m}^{3}\right], \lambda$ - thermal conductivity $[\mathrm{W} / \mathrm{mK}], \kappa_{\text {app }}-$ apparent moisture diffusivity $\left[\mathrm{m}^{2} / \mathrm{s}\right]$.

Table 1: Material characteristics of thermal insulations

\begin{tabular}{|l|c|c|c|}
\hline & $\begin{array}{c}\text { Expanded } \\
\text { polystyrene }\end{array}$ & $\begin{array}{c}\text { Rockwool } \\
\text { hydrophobic } \\
\text { mineral wool } \\
\text { (HFOB) }\end{array}$ & $\begin{array}{c}\text { Rockwool } \\
\text { hydrophilic } \\
\text { mineral wool } \\
\text { (HFIL) }\end{array}$ \\
\hline \hline$\rho\left[\mathrm{kg} / \mathrm{m}^{3}\right]$ & 16.5 & 100 & 170 \\
\hline$\psi[\%]$ & 98.4 & 96.6 & 92.9 \\
\hline$c[\mathrm{~J} / \mathrm{kgK}]$ & 1570 & 790 & 770 \\
\hline$\mu_{\text {dry cup }}[-]$ & 58 & 2.6 & 1.6 \\
\hline$\mu_{\text {wet cup }}[-]$ & 29 & 1.3 & 0.041 \\
\hline$\lambda_{\text {dry }}[\mathrm{W} / \mathrm{mK}]$ & 0.037 & 0.036 & 0.694 \\
\hline$\lambda_{\text {sat }}\left[\mathrm{W} / \mathrm{mK}^{2}\right]$ & 0.0513 & 0.766 & $4.1 \mathrm{e}-05$ \\
\hline$\kappa_{\text {app }}\left[\mathrm{m}^{2} / \mathrm{s}\right]$ & $1.5 \mathrm{e}-09$ & $6.1 \mathrm{e}-11$ & 0.000539 \\
\hline$w_{\text {hyg }}\left[\mathrm{m}^{3} / \mathrm{m}^{3}\right]$ & 0.0001776 & 0.00021 & \\
\hline
\end{tabular}


Table 2: $\quad$ Material characteristics of other materials.

\begin{tabular}{|l|c|c|c|}
\hline & AAC P1.8-300 & $\begin{array}{c}\text { Mamut M2 } \\
\text { mortar }\end{array}$ & $\begin{array}{c}\text { Baumit MVR } \\
\text { Uni }\end{array}$ \\
\hline \hline$\rho\left[\mathrm{kg} / \mathrm{m}^{3}\right]$ & 304 & 1430 & 1402 \\
\hline$\psi[\%]$ & 87.4 & 42.6 & 44.4 \\
\hline$c[\mathrm{~J} / \mathrm{kgK}]$ & 1080 & 1020 & $1020-1780$ \\
\hline$\mu_{\text {dry cup }}[-]$ & 7.10 & 12.40 & 12.4 \\
\hline$\mu_{\text {wet cup }}[-]$ & 2.20 & - & 4.5 \\
\hline$\lambda_{\text {dry }}[\mathrm{W} / \mathrm{mK}]$ & 0.075 & 0.481 & 0.443 \\
\hline$\lambda_{\text {sat }}[\mathrm{W} / \mathrm{mK}]$ & 0.704 & 2.022 & 1.380 \\
\hline$\kappa_{\text {app }}\left[\mathrm{m}^{2} / \mathrm{s}\right]$ & $2.08 \mathrm{e}-09$ & $1.07 \mathrm{e}-9$ & $1.59 \mathrm{e}-9$ \\
\hline$w_{\text {hyg }}\left[\mathrm{m}^{3} / \mathrm{m}^{3}\right]$ & 0.0152 & 0.0201 & 0.042 \\
\hline
\end{tabular}

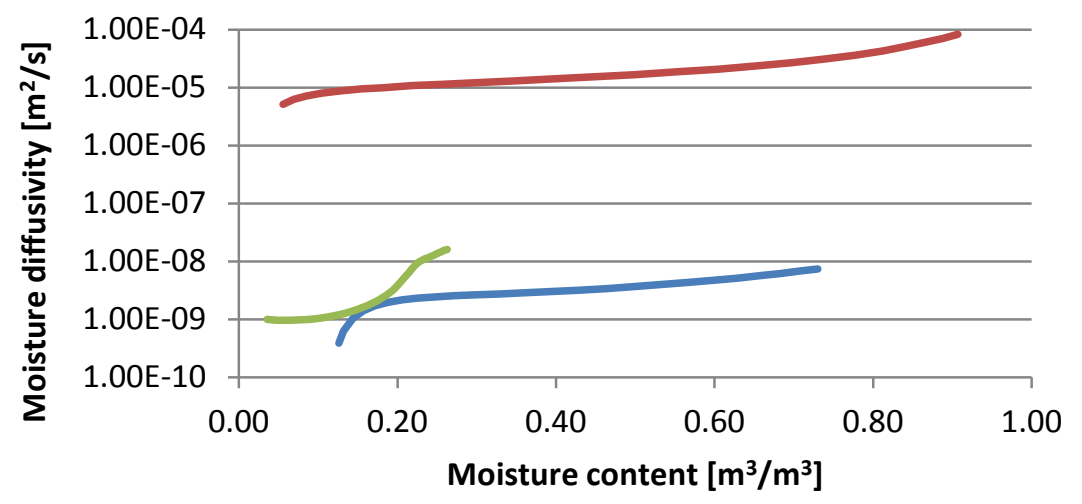

$\longrightarrow$ HFOB $\longrightarrow$ HFIL $=A A C$ P $1.8-300$

Figure 1: Moisture diffusivity as a function of moisture content

\subsection{Boundary conditions and time interval of simulation}

Because the boundary conditions should be as realistic as possible, climatic data in the exterior in the form of Test Reference Year for Prague was used. Test reference year contains average data for 30 years. On the interior side we used constant value of relative humidity $55 \%$ and temperature $21^{\circ} \mathrm{C}$ (see Fig. 2). The climatic data were obtained using Meteonorm software [8]. The simulation 
started with the data for $1^{\text {st }}$ July and was performed for 5 consecutive years. The presented results refer to the last simulated year where the effect of initial conditions was assumed to vanish.

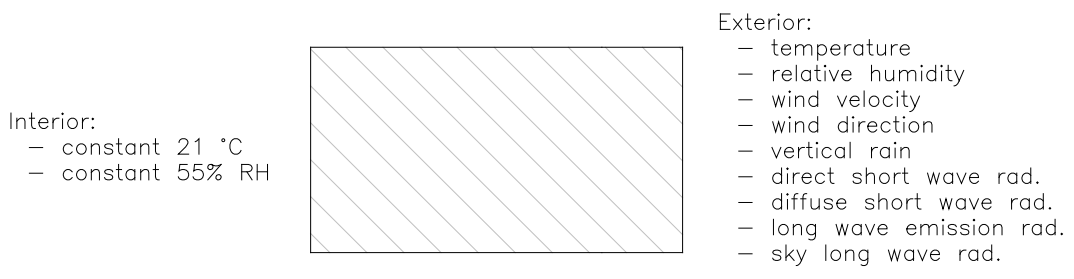

Figure 2: Boundary conditions

\section{Computational results}

Analyzed moisture and temperature profiles are presented in a set of figures which are given below. Each figure contains vertical lines corresponding to the material interfaces described in Section 2.2. In these figures, interior is on the left side, that means, the layers are sorted in order (from left side): interior plaster, AAC block, connecting layer, thermal insulation and exterior plaster.

\subsection{Temperature field}

Figure 3 shows temperature profiles of building envelopes in a typical winter day $\left(15^{\text {th }}\right.$ January). The differences between temperature values are not so high, however they are apparent particularly in the zone of connecting layer. The highest temperatures are obtained when building envelope with expanded polystyrene with moisture dependent parameters is assumed. On the other hand, lowest values are obtained when hydrophilic mineral wool assuming constant material parameters is under consideration.

Temperature profiles in a typical summer day are captured in Figure 4. Similarly to the previous case, the differences are not very significant but they are apparent in the AAC block near to the material interface between AAC and connecting layer. The lowest temperature values are obtained when hydrophilic mineral wool assuming constant material parameters is considered, the highest values are given when hydrophobic mineral wool assuming moisture dependent material parameters is considered.

The differences between simulation results assuming constant and moisture dependent parameters are obvious at most in Figure 5, where building envelope provided with expanded polystyrene is presented. The highest difference was detected on the material interface between AAC block and connecting layer and reached $1.2^{\circ} \mathrm{C}$, which is approximately $0.5 \%$. 


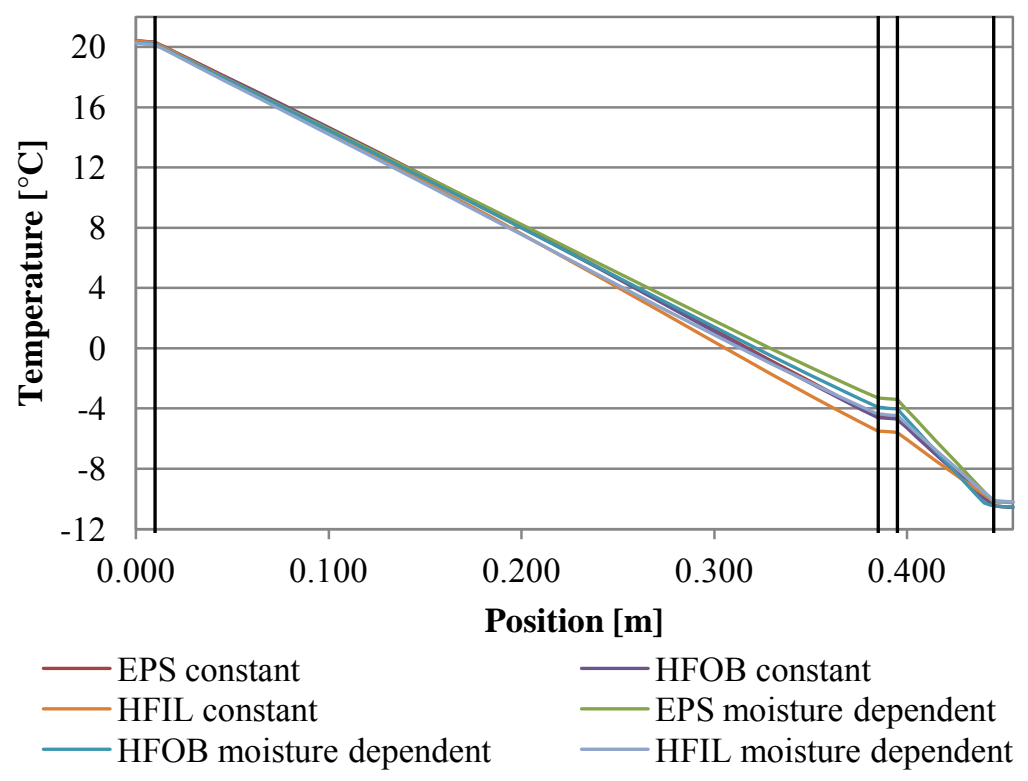

Figure 3: Temperature profiles in a typical winter day.

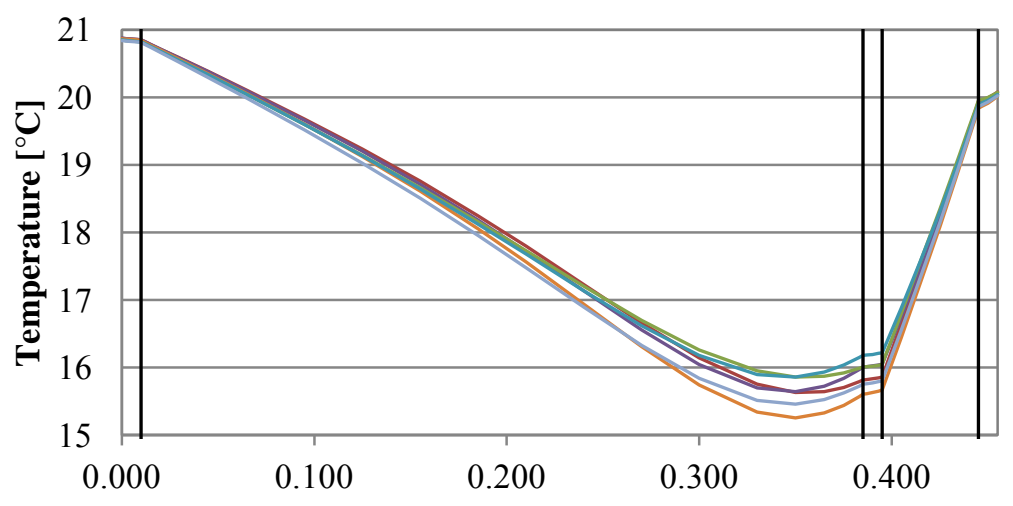

\section{Position [m]}
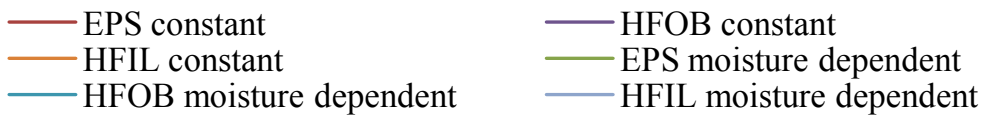

Figure 4: Temperature profiles in s typical summer day. 


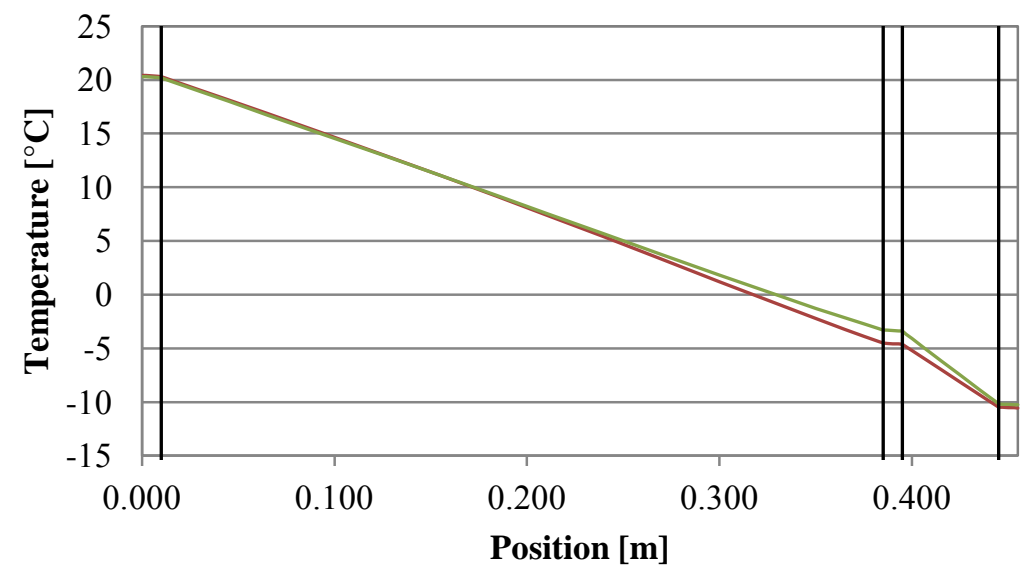

- EPS constant $\quad$ EPS moisture dependent

Figure 5: Temperature differences between simulation results assuming constant and moisture dependent parameters.

\subsection{Moisture field}

As the moisture transport and accumulation parameters of investigated thermal insulating materials were significantly different (see Table 1), it was to be expected that relative humidity profiles will differ more substantially than temperature fields. This was confirmed, as it is illustrated in the relative humidity profiles in Figure 6.

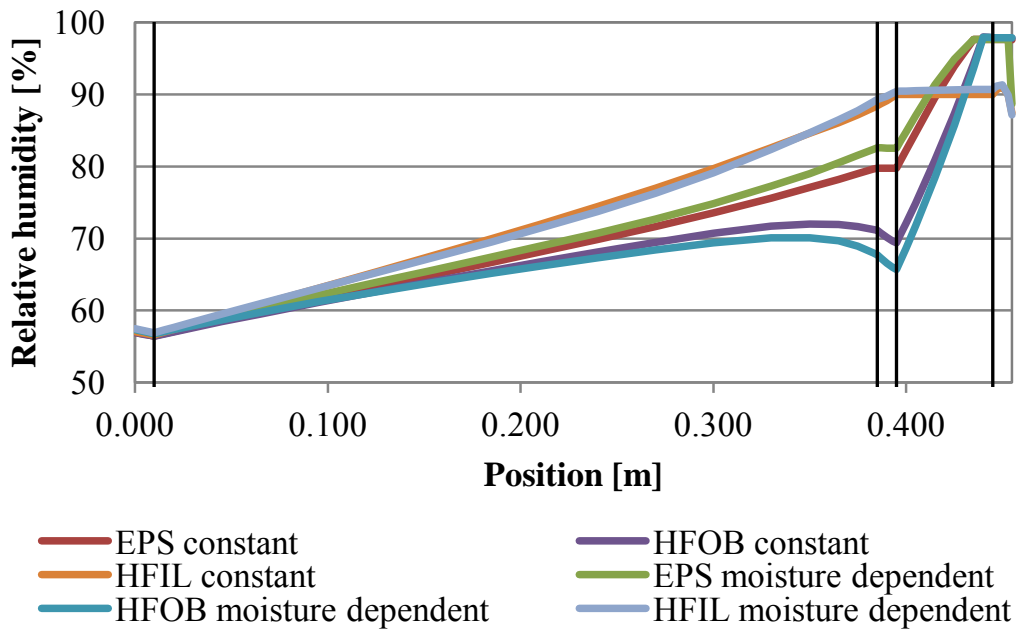

Figure 6: Relative humidity profiles in typical winter day. 
The highest differences (Fig. 6) in relative humidity are located near the connecting layer and reach almost $22 \%$. The highest relative humidity is obtained when hydrophilic mineral wool is assumed.

In the case of the relative humidity profiles in summer period (Figure 7), the highest values are achieved when expanded polystyrene is assumed. However, while during the winter period the differences between particular variations were almost $22 \%$, during summer period it is only $11 \%$.

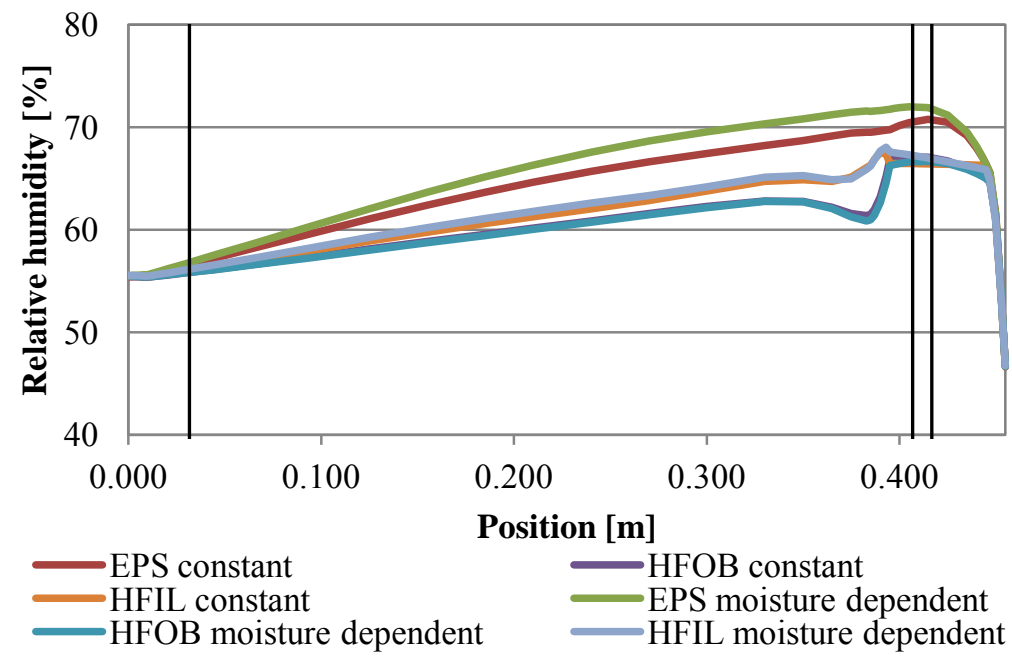

Figure 7: Relative humidity profiles in typical summer day

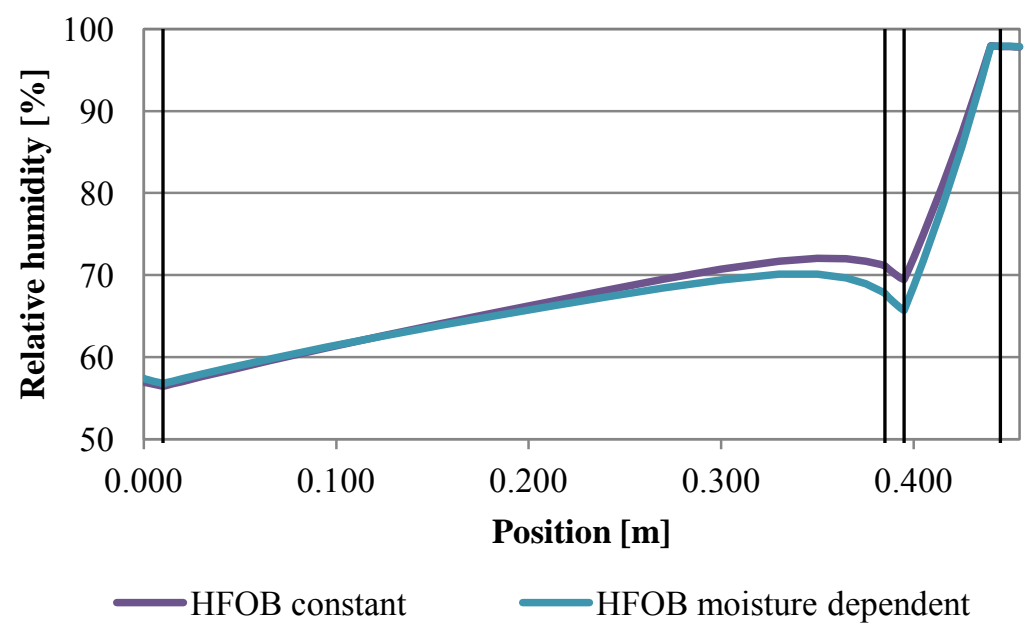

Figure 8: Relative humidity differences between simulation results assuming constant and moisture dependent parameters. 
According to the results presented in Figure 8, the building envelope provided with hydrophobic mineral wool seems to be the most sensitive to the quality of input material parameters. The differences between simulation results assuming constant or moisture dependent values of material parameters is 3.72 percentage points of relative humidity.

\subsection{Energy efficiency}

Annual energy consumption is calculated as integral of time function of heat flux according to the relation

$$
Q=\int_{1 \text { Jan }}^{31 D e c} q(t) d t,
$$

where $Q$ denotes the energy efficiency per annum $\left[\mathrm{kWh} / \mathrm{m}^{2}\right.$ envelope $\left.\mathrm{a}\right]$ and $q(t)$ is time function of heat flux $\left[\mathrm{W} / \mathrm{m}^{2}\right.$ envelope $]$ calculated from nodal temperatures in interior boundary element,

$$
q=-\lambda \frac{d T}{d x}
$$

where $q$ denotes the heat flux [W/ $\mathrm{m}^{2}$ envelope $], \lambda$ is thermal conductivity $[\mathrm{W} / \mathrm{mK}]$, $d T$ is difference between temperatures of two nodes defining the element $[\mathrm{K}]$ and $d x$ is size of the element $[\mathrm{m}]$.

The value of thermal conductivity $\lambda$ is determined from calculated moisture content according to the linear function characterized by values of $\lambda_{d r y}$ and $\lambda_{\text {sat }}$ in Table 2 of Baumit MVR Uni plaster.

Figure 9 compares hourly values of heat fluxes of investigated types of building envelope. The differences in hourly values are low, but integration of their time function according to (4) reveals relative distinctions (see Table 3).

Table 3: Annual energy consumption of the studied envelopes.

\begin{tabular}{|l|c|}
\hline Thermal insulation & $\begin{array}{c}\text { Annual energy consumption } \\
{\left[\mathrm{kWh} / \mathrm{m}_{\text {envelope }}^{2}\right]}\end{array}$ \\
\hline \hline EPS - constant & 18.743 \\
\hline EPS - moisture dependent & 19.954 \\
\hline HFOB - constant & 18.788 \\
\hline HFOB - moisture dependent & 19.875 \\
\hline HFIL - constant & 19.535 \\
\hline HFIL - moisture dependent & 21.021 \\
\hline
\end{tabular}




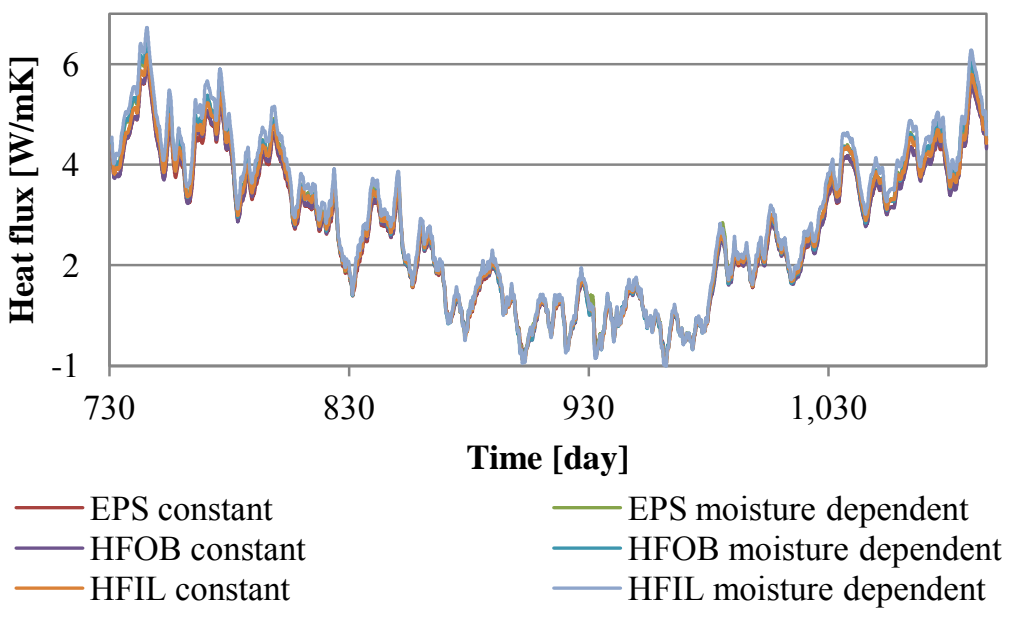

Figure 9: Heat fluxes on interior side

Assuming only constant values of material characteristics, best results are achieved when expanded polystyrene is used. However, taking into account the effect of moisture content, the best energy efficiency is obtained for building envelope provided with hydrophobic mineral wool.

\section{Discussion}

Based on the results presented in this paper it is obvious that the quality of simulation outputs is closely related to the quality of input parameters. Therefore, during experimental analysis it is essential to focus on measuring not only constant values of materials characteristics, but also on their dependence on moisture content.

Temperature field of building envelope is primarily influenced by thermal conductivity of materials which are involved. Considering the fact, this parameter can be increased due to moisture up to 10-20 times (see Tables 2 and 3 ). More convenient, but not correct results will be obtained, when constant material parameters will be assumed. This is proved by results presented in Figures 3-5. Temperatures across the envelope as result of simulation assuming only constant values of material characteristics are lower than results of simulation with moisture dependent values. The highest temperature difference was detected on the material interface between AAC block and connecting layer and reached $1.2^{\circ} \mathrm{C}(0.5 \%)$ (building envelope with expanded polystyrene - see Fig. 5). This value seems to be very small; however it can lead to underestimation of water vapour condensation inside building envelope. Unfortunately, possible condensation can be located near to the connecting layer between AAC block and thermal insulation, so its damage may lead to separation of layers. 
Deterioration of thermal properties will also negatively affect energy efficiency of building envelope. According to the results presented in Figure 9 and Table 3, poor quality of input data can create incorrect image about thermal capability of building envelope and magnitude of the error can be up to $7 \%$. It is also worth to mention that from the point of view of energy efficiency, expanded polystyrene seems to be the best choice when only constant material parameters are assumed, while under real conditions hydrophobic mineral wool gives slightly better results (see Table 3). Similar discrepancies are often misused by producers of building materials presenting only dry state values of their products.

The moisture diffusivity influencing moisture field inside building envelope at most is far from a constant as it is obvious in Figure 1. Therefore, there are differences in simulation results based on different approaches (assuming moisture dependent or only constant material parameters). The graphs presented in Figures 6 and 7 show that hydrophilic mineral wool gives almost identical results during the year, regardless of quality of used material characteristics. Building envelope with expanded polystyrene gives worse results, when moisture dependent material parameters are used. The difference is 1 percentage point of relative humidity. The biggest difference is obtained in summer when building envelope provided with hydrophobic mineral wool is assumed (see Fig. 8). However, in case of moisture fields, all the differences are on the safety side, because better results are obtained when moisture dependent material parameters are used.

\section{Conclusions}

In this paper, effect of moisture dependent thermal and hygric parameters on the moisture and temperature fields in building envelopes was analyzed. The studied envelope consisted of AAC (as load bearing material) provided with thermal insulation (expanded polystyrene, hydrophobic and hydrophilic mineral wool) and exterior and interior plaster. It was confirmed that the presence of moisture in building materials affects many of their parameters, one the most significantly impacted are thermal properties. During their service life, building materials contain almost permanently certain amount of moisture, thus it is necessary to calculate with their deterioration. The producers of building materials very often present only values in dry state, but this can be very misleading. It is necessary to point out that the quality of input parameters has a significant impact on the quality of calculation results. This was proved quite clearly in this paper. Regarding this fact, the primary experimental analysis of porous materials must be done very well. If the quality of input parameters is not so good (e.g., the dependence on moisture content could not be measured), it is essential to consider the possible uncertainties of the computations and to perform at least a sensitivity analysis within the expected margin of error. 


\section{Acknowledgement}

This research has been supported by the Czech Science Foundation, under project No P105/12/G059.

\section{References}

[1] Černý, R., Complex System of Methods for Directed Design and Assessment of Functional Properties of Building Materials: Assessment and Synthesis of Analytical Data and Construction of the System. Czech Technical University in Prague, pp. 192 - 201, 2010.

[2] Kočí, V., Kočí, J., Maděra, J., Černý, R., Computer code HEMOT for hygrothermal assessment of thermal insulation systems. Thermophysics 2010. Brno: University of Technology, pp. 133-140, 2010.

[3] Kruis, J., Koudelka, T. \& Krejčí, T., Efficient computer implementation of coupled hydro-thermo-mechanical analysis. Mathematics and Computers in Simulation, 80, pp. 1578-1588, 2010.

[4] Künzel, H. M., Simultaneous Heat and Moisture Transport in Building Components, PhD Thesis, IRB Verlag Stuttgart, 1995.

[5] Jerman, M., Černý, R., Effect of Moisture Content on Heat and Moisture Transport and Storage Properties of Thermal Insulation Materials. Energy and Buildings, 53, pp. 39-46, 2012.

[6] Jerman, M., Kočí, V., Maděra, J., Výborný, J., Černý, R. Water and heat transport parameters of materials involved in AAC-based building envelopes, in 1st Central European Symposium on Building Physics. Lodz: Technical University of Lodz, pp. 39-45, 2010.

[7] Jerman, M., Kočí, V., Výborný, J., Černý, R. Thermal and hygric properties of autoclaved aerated concrete In: Thermophysics 2010. Brno: University of Technology, 2010, p. 102-108.

[8] Meteonorm Version 6, software version 6.1.0.20 of April 2010, METEOTEST, Switzerland, 2010. 